\title{
Analisis Parameter Signal to Noise Ratio dan Bit Error Rate dalam Backbone Komunikasi Fiber Optik Segmen Lamongan-Kebalen
}

\author{
Rima Fitria Adiati, Apriani Kusumawardhani, dan Heru Setijono \\ Departemen Teknik Fisika, Fakultas Teknologi Industri, Institut Teknologi Sepuluh Nopember (ITS) \\ email: apri@ep.its.ac.id
}

\begin{abstract}
Abstrak-Fiber optik telah menjadi solusi atas meningkatnya kebutuhan transfer data dengan kapasitas tinggi. Dengan 4.3 juta pelanggan dan proyeksi pertumbuhan sebesar $18.3 \%$ pertahun, sektor fixed broadband PT Telkom Indonesia bergantung pada kualitas infrastruktur backbone fiber optik, yang direpresentasikan melalui parameter Signal to Noise Ratio (SNR) dan Bit Error Rate (BER). Oleh karena itu, perlu dilakukan analisis terhadap parameter SNR dan BER pada segmen backbone fiber optik antara STO Lamongan 1 dan STO Kebalen, Surabaya. SNR merupakan perbandingan logaritmik antara daya sinyal dan noise yang diterima receiver, sedangkan BER adalah ukuran intensitas terjadinya error pembacaan bit data. Pengukuran di receiver STO Kebalen menghasilkan BER $10^{-23}$. Analisa SNR dan BER secara keseluruhan dilakukan melalui simulasi software Optisystem. Backbone 100 Gbps, 84 km dengan sistem DWDM 10 channel ini disimulasikan pada frekuensi 193.1 - 194 THz dengan spacing $100 \mathrm{GHz}$ antar channel. Hasil simulasi menunjukkan nilai SNR dan BER memenuhi standar dan dipengaruhi frekuensi atau panjang gelombang di setiap channel. SNR maksimum adalah 72.37 pada 193.6 THz dan nilai BER minimum yaitu $2.05 \times 10^{-30}$ pada 193.5 THz. Untuk mendapatkan nilai BER optimum yaitu $10^{-12}$, dilakukan pemasangan dispersion compensating fiber serta penambahan daya transmitter pada channel berfrekuensi 193.1, 193.2, 193.9, dan 194 THz.
\end{abstract}

Kata Kunci-BER, DWDM, Optisystem, SNR.

\section{PENDAHULUAN}

U NTUK mampu menyokong peningkatan kebutuhan akses internet masyarakat yang meningkat tajam baik pada sektor mobile dan fixed, diperlukan sistem komunikasi fiber optik yang didukung jaringan backbone dengan kapasitas tinggi. Hingga saat ini, backbone jaringan fiber optik telah mampu mengirimkan data dengan bandwidth total 4 terabit per sekon. Nilai tersebut diperoleh melalui 100 channel DWDM dengan bit rate $4 \mathrm{~Gb} / \mathrm{s}$ pada setiap channelnya.[1]

Mengingat pentingnya backbone jaringan sebagai infrastruktur komunikasi, maka perlu dilakukan desain dan monitoring dengan memperhatikan berbagai hal. Signal to noise Ratio (SNR), Bit Error Rate (BER), dan Q-factor merupakan parameter kunci yang menentukan performa suatu channel komunikasi [2]. Tujuan utama dari suatu transmisi sinyal optik adalah untuk mencapai nilai BER yang diinginkan diantara dua node atau titik dalam jaringan. Banyak hal dapat menyebabkan loss dalam sistem komunikasi fiber optik diantaranya atenuasi (absorpsi, scattering, bending loss [3]) dan distorsi.

Untuk dapat mengetahui parameter yang mempengaruhi BER dan SNR, simulasi dilakukan menggunakan software Optisystem. Beberapa referensi telah menunjukkan kemudahan penggunaan software tersebut untuk mendesain dan menganalisa suatu jaringan optik [4][5][6]. Pada studi ini, dilakukan pengukuran dan simulasi parameter SNR dan BER pada segmen backbone fiber optik STO Lamongan 1 -STO Kebalen sehingga dapat diketahui performa jaringan tersebut.

\section{URAIAN PENELITIAN}

A. Dasar Teori

1) Dense Wavelength Division Multiplexing (DWDM)

DWDM merupakan suatu teknik komunikasi multichannel, yaitu beberapa channel optik dengan panjang gelombang atau frekuensi berbeda berada dalam satu kabel fiber optik. Kerapatan frekuensi (spacing) merupakan hal yang membedakan DWDM terhadap jenis WDM yang lain. Berdasarkan standar ITU-T G.671 sistem WDM dibagi menjadi 3 [7] yaitu

a. Coarse WDM. Menggunakan spacing antar channel antara $1000 \mathrm{GHz}(8 \mathrm{~nm})$ dan $50 \mathrm{~nm}$.

b. Dense WDM. Memiliki spacing kurang dari $1000 \mathrm{GHz}$

c. Wide WDM. Memiliki spacing sangat lebar yaitu lebih dari $50 \mathrm{~nm}$.

\section{2) Signal to Noise Ratio (SNR)}

Pada semua jenis sistem transmisi data, signal to noise ratio (SNR) merupakan parameter yang harus diperhatikan. SNR digunakan untuk menunjukkan seberapa banyak noise mengganggu sinyal yang ditransmisikan. Dengan kata lain, SNR membandingkan daya sinyal yang diinginkan terhadap background noise.

Untuk mengukur SNR, diperlukan instrumen Optical Spectrum Analyser (OSA). Nilai OSNR tidak dipengaruhi oleh format data, bentuk pulsa, atau bandwidth sistem, melainkan hanya daya sinyal dan noise yang terbaca di OSA [8], yaitu:

$$
\mathrm{SNR}=10 \log \frac{\mathrm{P}_{\text {signal }}}{\mathrm{P}_{\text {noise }}}
$$

SNR dapat pula dinyatakan dalam variabel $Q$-factor. $Q$ factor merepresentasikan optical SNR untuk komunikasi optik biner/digital dan memudahkan analisis performa system [8]. 
Persamaan dibawah digunakan untuk dapat memberikan hubungan antara OSNR, $Q$-factor, dan BER.

$$
\mathrm{Q}=\frac{2 \sqrt{2} \text { OSNR }}{1+\sqrt{1+40 \mathrm{ONR}}}
$$

\section{3) Bit Error Rate (BER)}

Sinyal optik yang dikirimkan melalui jaringan FTTH berupa pulsa-pulsa cahaya yang masing-masing membawa satu bit data [8]. Tidak semua bit dapat terkirim sempurna. BER didefinisikan sebagai jumlah terjadinya error tiap jumlah bit data terkirim [9] pada suatu sistem digital. Apabila jumlah bit error adalah $N_{E}$ dan jumlah bit total terkirim adalah $N_{T}$ maka[10]

$$
\mathrm{BER}=\frac{\mathrm{N}_{\mathrm{E}}}{\mathrm{N}_{\mathrm{T}}}
$$

Pada jaringan komunikasi optik secara umum, nilai BER yang harus dipenuhi adalah BER $10^{-6}-10^{-12}$. Artinya, tiap $10^{9}$ hingga $10^{12}$ bit data yang dikirim, error yang terjadi hanyalah pada 1 bit. BER juga disebut dengan error probability $\left(\mathrm{P}_{\mathrm{e}}\right)$, atau probabilitas munculnya error dalam transmisi data. Dalam proses transmisi, bit tertentu memiliki amplitudo sinyal yang terlalu dekat dengan threshold sehingga tidak dapat dibedakan nilainya dengan benar.[11]. Nilai BER dapat pula dinyatakan dalam $Q$-factor melalui persamaan berikut [10].

$$
\mathrm{BER}=\mathrm{P}_{\mathrm{e}}(\mathrm{Q}) \approx \frac{1}{\sqrt{2 \pi}} \frac{\mathrm{e}^{-\mathrm{Q}^{2} / 2}}{\mathrm{Q}}
$$

\section{B. Metodologi Penelitian}

Metodologi yang digunakan terdiri dari beberapa tahap hingga menghasilkan analisa data nilai BER dan SNR dari backbone fiber optik. Langkah utama dalam studi ini adalah pengambilan data spesifikasi jaringan backbone dan simulasi. Gambar 1 merupakan diagram alir dari penelitian ini.

Tabel 1 berikut adalah hasil dari pengambilan data berupa spesifikasi komponen jaringan yang akan digunakan dalam simulasi.

Tabel 1.

Spesifikasi backbone Lamongan-kebalen

\begin{tabular}{ll}
\hline \hline \multicolumn{1}{c}{ Komponen } & \multicolumn{1}{c}{ Spesifikasi } \\
\hline $\begin{array}{l}\text { Optical Transport Network (OTN) } \\
\text { Platform }\end{array}$ & Huawei Optix OSN 8800 T32 \\
$\begin{array}{l}\text { Bit Rate } \\
\text { Wavelength range }\end{array}$ & $10 \mathrm{Gbps}, 40 \mathrm{Gbps}$, atau 100 Gbps \\
& $192.1-196.05 \mathrm{THz}$ (Band-C, ITU-T \\
$\begin{array}{l}\text { Bit rate maksimum tiap } \\
\text { channel }\end{array}$ & $100 \mathrm{G}(\mathrm{OTU} 4)$ \\
Fiber interface & G.652, G.653, G.654, G.655 \\
Fiber optik & Voksel G.655C \\
Atenuasi maksimum & $0.3 \mathrm{~dB} / \mathrm{km}(\mathrm{estimasi}$ termasuk \\
& konektor dan splice loss) \\
Dispersi kromatik & $18 \mathrm{Ps} /(\mathrm{nm} . \mathrm{km})$ \\
Dispersion slope & $0.095 \mathrm{Ps} /\left(\mathrm{nm}{ }^{2} . \mathrm{km}\right)$ \\
\hline \hline
\end{tabular}

\section{HASIL DAN PEMBAHASAN}

\section{A. Hasil Pengukuran Bit Error Rate (BER)}

Pengukuran BER menggunakan instrumen BER Tester dilakukan selama 24 jam untuk memenuhi persyaratan PT
Telkom Indonesia terkait uji terima backbone jaringan. Pengukuran dilaukan di slot 20, node ID 25 dengan board type T210. Jenis pengukuran ini dikategorikan sebagai trafic generation and monitoring, artinya nilai BER dipantau secara sampling pada salah satu channel selama 24 jam untuk mengetahui apakah suatu backbone memenuhi nilai pass. Dalam persyaratan uji terima PT Telkom Indonesia, nilai BER yang memenuhi nilai pass adalah BER $10^{-23}$. Dengan kata lain, setiap $10^{23}$ bit data terkirim, terdapat 1 bit data yang error saat tiba di receiver.

\section{B. Simulasi Backbone Segmen Lamongan-Kebalen}

Simulasi dalam studi ini dilakukan menggunakan software Optisystem. Parameter-parameter yang digunakan dalam simulasi mengikuti spesifikasi komponen jaringan yang diukur sebelumnya. Secara global, parameter yang digunakan dalam simulasi diringkas dalam tabel 2 sedangkan rancangan visual dalam software ditunjukkan oleh gambar 2 .

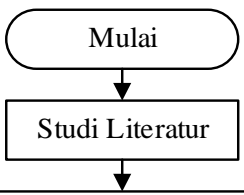

Identifikasi jaringan backbone, persiapan pengambilan data

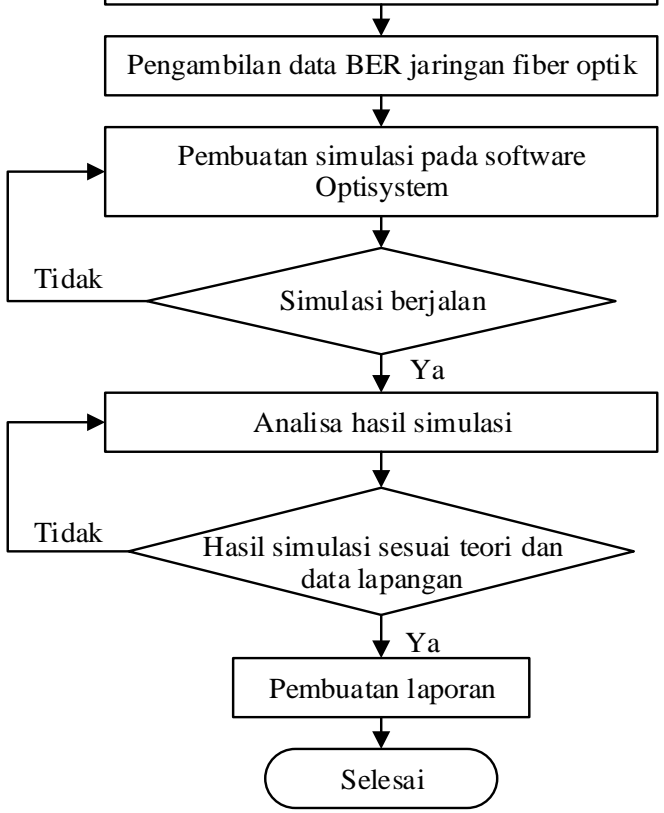

Gambar 1. Diagram alir penelitian

Backbone jaringan fiber optik STO Lamongan 1 - STO Kebalen merupakan suatu link dengan panjang $84 \mathrm{~km}$. Parameter pada tabel 2 digunakan sebagai dasar pembuatan simulasi. Berdasarkan kondisi nyata, digunakan 10 channel DWDM dengan bit rate masing-masing channel sebesar 10 Gbps. Panjang gelombang tiap channel diatur melalui parameter frekuensi $\mathrm{CW}$ laser. Komponen $\mathrm{CW}$ laser menggunakan frekuensi $193.1 \mathrm{THz}$, atau setara panjang gelombang $1552.52 \mathrm{~nm}$.

Berdasarkan standar ITU-T G.671[12], pada simulasi ini digunakan DWDM dengan spacing sebesar $100 \mathrm{GHz}$. Artinya, 
setiap channel pada sistem ini akan memiliki selisih frekuensi sebesar $100 \mathrm{GHz}$ atau setara panjang gelombang $0.8 \mathrm{~nm}$. Pengaturan ini dapat dilakukan melalui menu parameter groups pada software optisystem.

Transmitter terdiri atas 4 bagian yaitu bit sequence generator, NRZ pulse generator, CW laser, dan MZ Modulator. Receiver memiliki komponen utama berupa photodetector, filter, dan regenerator. Alat ukur diantaranya WDM analyzer, optical spectrum analyzer (OSA), optical power meter (OPM), dan BER analyzer dipasang pada sistem.

Tabel 2.

Parameter dalam simulasi

\begin{tabular}{lll}
\hline \hline Parameter & Nilai & Satuan \\
\hline Global parameter & & \\
Bit rate & $10^{9}$ & $\mathrm{Bit} / \mathrm{s}$ \\
Sequence length & 128 & $\mathrm{Bit}$ \\
$\quad \begin{array}{l}\text { Sampel per bit } \\
\text { Jumlah channel }\end{array}$ & 64 & \\
Laser Source & 10 & \\
$\quad$ Frequency & & \\
$\quad$ Power & $193.1-194$ & $\mathrm{THz}$ \\
Fiber Optik & 20 & $\mathrm{dBm}$ \\
$\quad$ Atenuasi maksimum & 0.3 & $\mathrm{~dB} / \mathrm{km}$ \\
$\quad \begin{array}{l}\text { Dispersi kromatik } \\
\text { Dispersion slope }\end{array}$ & 18 & $\mathrm{ps} /(\mathrm{nm} \cdot \mathrm{km})$ \\
PMD coefficient & 0.090 & $\mathrm{ps} /\left(\mathrm{nm}{ }^{2} . \mathrm{km}\right)$ \\
Effective Area & 0.2 & $\mathrm{ps} / \mathrm{km}$ \\
Receiver & 80 & $\mu m^{2}$ \\
Dark current & & \\
\hline \hline
\end{tabular}

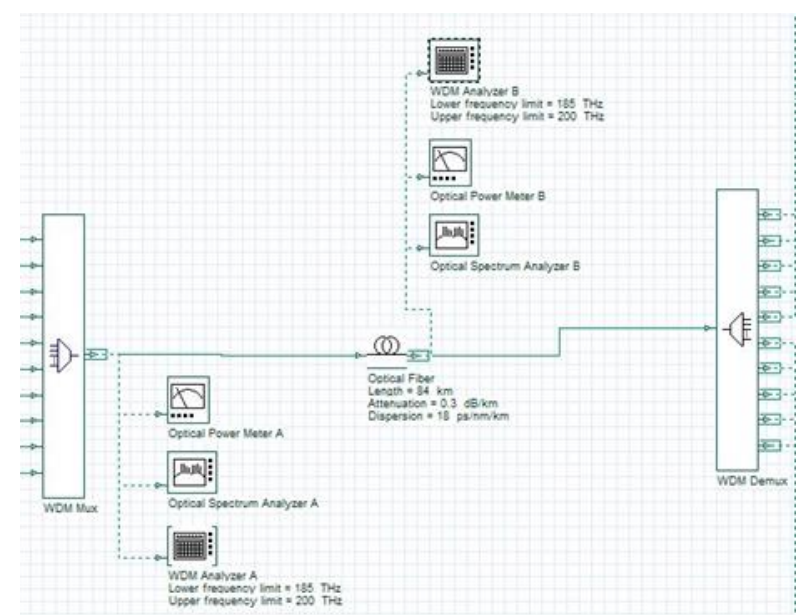

Gambar 2. Simulasi link fiber optik dalam software

\section{Analisis Hasil Simulasi Signal to Noise Ratio (SNR) dan Bit Error Rate (BER)}

Dua alat ukur penting yang berkaitan dengan SNR adalah OSA dan WDM analyzer. OSA menunjukkan grafik spektrum cahaya sedangkan WDM analyzer menghasilkan data berupa tabel. Data tersebut diringkas pada gambar 3. Simulasi menunjukkan bahwa nilai SNR pada seluruh channel telah memenuhi rekomendasi untuk link backbone $10 \mathrm{Gbps}$ yaitu minimal $25 \mathrm{~dB}$. SNR juga cukup stabil diantara nilai 50 hingga 56, dengan kenaikan cukup tajam pada frekuensi 193.5 dan 193.6 THz. Nilai SNR tertinggi diperoleh pada channel 6 dengan SNR 72.3721.

Bit error rate adalah salah satu cara untuk mengetahui kualitas sinyal yang dikirimkan melalui sistem komunikasi fiber optik. Melalui BER analyzer dalam software optisystem, dapat dihasilkan nilai BER, sekaligus grafik $Q$-factor dan eye diagram. Sama halnya pada SNR, BER dianalisa dalam tiga kondisi yaitu kondisi normal, saat penambahan DCF, dan saat penambahan daya transmitter. Hasil simulasi ditunjukkan di tabel 4 dan gambar 4.

Pada simulasi untuk menentukan bit error rate dihasilkan nilai BER yang bervariasi pada channel yang berbeda. Semua frekuensi telah memenuhi standar minimum BER untuk komunikasi fiber optik, walaupun hasilnya tidak sama rata. Grafik BER dengan jelas menunjukkan adanya pengaruh frekuensi atau panjang gelombang terhadap nilai BER. Hal ini berkaitan dengan karakteristik fiber optik dan receiver yang memiliki daerah kerja puncak pada $1550 \mathrm{~nm}$. Semakin jauh panjang gelombang dari nilai tersebut, semakin besar loss yang terjadi sehingga secara tidak langsung akan menurunkan nilai BER. Namun, atenuasi bukanlah satu-satunya faktor yang mempengaruhi nilai BER.

\section{Pengaruh Penambahan Dispersion Compensating Fiber (DCF) dan Daya Transmitter terhadap BER}

Berdasarkan hasil simulasi BER pada tabel 3, semua channel telah memenuhi standar komunikasi fiber optik dan dapat beroperasi. Namun demikian, dapat dilakukan upaya untuk menurunkan nilai BER sehingga performa sistem menjadi optimal. Selain simulasi dengan mengikuti kondisi backbone yang sebenarnya, simulasi untuk menemukan upaya peningkatan peforma backbone STO Lamongan 1 - STO Kebalen juga dilakukan. Nilai BER optimum yang direkomendasikan PT Telkom Indonesia untuk backbone 100 Gbps adalah $10^{-12}$ sehingga terdapat 4 channel yang perlu diperhatikan. Cara pertama yang dilakukan adalah menghilangkan efek dispersi melalui Dispersion Compensating Fiber (DCF), dengan harapan meningkatkan nilai signal to noise ratio dan menurunkan nilai bit error rate dari sistem secara keseluruhan. Cara kedua adalah dengan menambahkan daya transmitter pada channel yang memiliki nilai BER diatas $10^{-12}$.

Dalam simulasi yang dilakukan sebelumya, parameter dispersi dirancang sesuai dengan datasheet fiber optik yaitu sebesar $18 \mathrm{ps} / \mathrm{km}$. DCF harus dapat mengurangi nilai tersebut hingga menjadi nol. Jika dinyatakan dalam suatu persamaan matematis maka [13]:

$$
\begin{aligned}
\left(D_{S M F}\right)\left(L_{S M F}\right) & =-\left(D_{D C F}\right)\left(L_{D C F}\right) \\
(18 \mathrm{ps} / \mathrm{km})(84 \mathrm{~km}) & =-(147 \mathrm{ps} / \mathrm{km})\left(L_{D C F}\right)
\end{aligned}
$$

Melalui persamaan diatas dihasilkan panjang DCF adalah $10.3 \mathrm{~km}$ untuk dispersi $-147 \mathrm{ps} / \mathrm{km}$. Berikut adalah data-data karakteristik DCF yang digunakan.

Tabel 3.

Perbandingan parameter SMF dan DCF

\begin{tabular}{lll}
\hline \hline Parameter & SMF & DCF \\
\hline Panjang fiber $(\mathrm{km})$ & 84 & 10.3 \\
Atenuasi maksimum $(\mathrm{dB} / \mathrm{km})$ & 0.3 & 0.24 \\
Dispersi kromatik $(\mathrm{ps} /(\mathrm{nm} . \mathrm{km}))$ & 18 & -147 \\
Dispersion slope $\left(\mathrm{ps} /\left(\mathrm{nm}^{2} . \mathrm{km}\right)\right)$ & 0.090 & 0.075 \\
\hline \hline
\end{tabular}




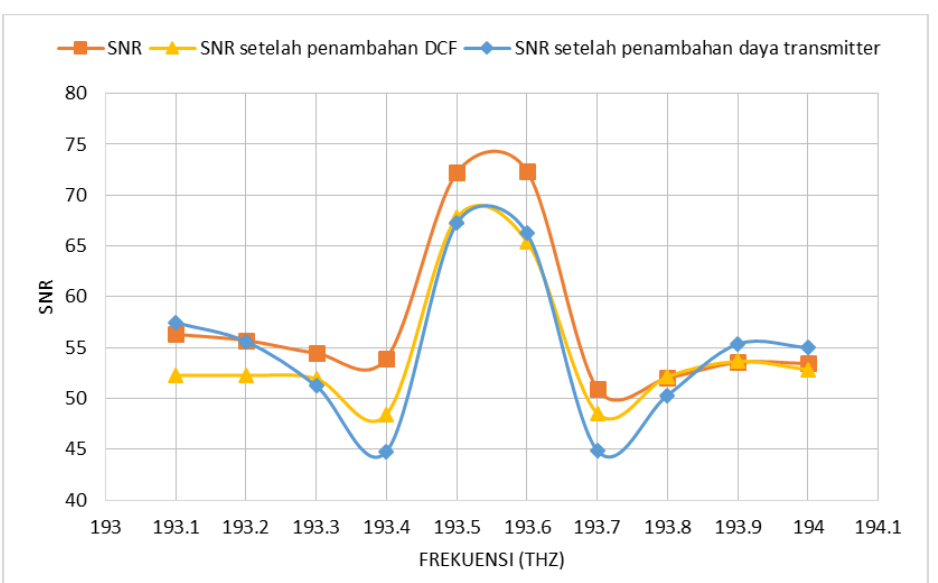

Gambar 3. Hasil simulasi SNR terhadap frekuensi

Tabel 4.

Hasil simulasi BER

\begin{tabular}{|c|c|c|c|c|c|c|c|c|}
\hline \multirow[t]{2}{*}{ Channel } & \multirow{2}{*}{$\begin{array}{l}\text { Frekuensi } \\
\text { (THz) }\end{array}$} & \multirow{2}{*}{$\begin{array}{c}\text { Panjang } \\
\text { gelombang }(\mathrm{nm})\end{array}$} & \multicolumn{2}{|c|}{ Kondisi normal } & \multicolumn{2}{|c|}{ Penambahan DCF } & \multicolumn{2}{|c|}{$\begin{array}{c}\text { Penambahan daya } \\
\text { transmitter }\end{array}$} \\
\hline & & & $Q$-factor & BER & $Q$-factor & BER & $Q$-factor & BER \\
\hline 1 & 193.1 & 1552.52 & 4.35 & 4.99E-06 & 7.93 & $9.76 \mathrm{E}-16$ & 8.17 & $1.10 \mathrm{E}-16$ \\
\hline 2 & 193.2 & 1551.72 & 6.17 & $2.89 \mathrm{E}-10$ & 8.66 & $2.31 \mathrm{E}-18$ & 7.68 & $7.59 \mathrm{E}-15$ \\
\hline 3 & 193.3 & 1550.92 & 6.87 & $2.48 \mathrm{E}-12$ & 9.16 & $2.38 \mathrm{E}-20$ & 8.21 & $9.97 \mathrm{E}-17$ \\
\hline 4 & 193.4 & 1550.12 & 8.75 & $1.04 \mathrm{E}-18$ & 10.18 & $1.17 \mathrm{E}-24$ & 9.29 & $6.96 \mathrm{E}-21$ \\
\hline 5 & 193.5 & 1549.32 & 11.40 & $2.05 \mathrm{E}-30$ & 9.89 & $1.75 \mathrm{E}-23$ & 11.65 & $1.14 \mathrm{E}-31$ \\
\hline 6 & 193.6 & 1548.51 & 11.19 & $2.15 \mathrm{E}-29$ & 11.79 & $2.04 \mathrm{E}-32$ & 11.48 & $7.21 \mathrm{E}-31$ \\
\hline 7 & 193.7 & 1547.72 & 9.61 & $3.03 \mathrm{E}-22$ & 10.77 & $1.88 \mathrm{E}-27$ & 9.65 & $1.88 \mathrm{E}-22$ \\
\hline 8 & 193.8 & 1546.92 & 9.07 & $5.16 \mathrm{E}-20$ & 14.28 & $1.39 \mathrm{E}-46$ & 8.45 & $1.2 \mathrm{E}-17$ \\
\hline 9 & 193.9 & 1546.12 & 5.57 & $8.66 \mathrm{E}-09$ & 13.00 & $5.22 \mathrm{E}-39$ & 8.94 & $1.64 \mathrm{E}-19$ \\
\hline 10 & 194 & 1545.32 & 4.50 & $2.24 \mathrm{E}-06$ & 12.33 & $2.90 \mathrm{E}-35$ & 6.58 & $1.43 \mathrm{E}-10$ \\
\hline
\end{tabular}

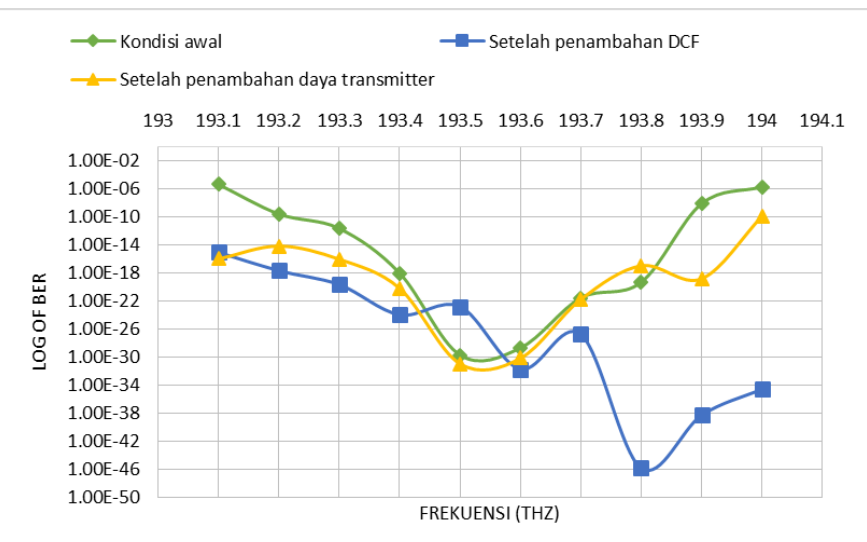

Gambar 4. Hasil simulasi BER terhadap frekuensi

Penambahan dispersion compensating fiber terbukti telah menurunkan bit error rate hampir di semua frekuensi, kecuali pada frekuensi $193.5 \mathrm{THz}$ BER naik menjadi $1.75 \times 10^{-23}$. Hal ini sesuai dengan teori bahwa DCF berhasil mengurangi efek dispersi namun fiber ini bekerja dalam range spektrum yang luas sehingga efek penurunan dispersi ini tidak merata di semua channel. Tampak di gambar 4 nilai BER mengalami penurunan namun tidak seimbang untuk tiap-tiap frekuensi. Namun demikian, tujuan untuk menurunkan nilai BER telah tercapai melalui teknik symmetrical compensation.

Salah satu cara lain yang dilakukan untuk menyeimbangkan nilai BER pada semua channel adalah dengan memberikan daya tambahan pada channel tertentu, dalam hal ini pada channel 1, 2, 9, dan 10 yang masih memiliki nilai BER diatas $10^{-12}$. Hasil dari simulasi menunjukkan grafik yang semakin landai, yaitu nilai BER yang menuju seimbang. Namun dengan simulasi ini masih belum dapat dicapai nilai BER $10^{-12}$ untuk channel 10 walaupun telah dilakukan penambahan power hingga $23 \mathrm{~dB}$. Dengan demikian solusi untuk meningkatkan nilai BER dengan lebih cepat adalah dengan penambahan DCF, walaupun akan memerlukan penambahan komponen tertentu. Solusi berupa peningkatan daya transmitter dapat digunakan sebagai solusi mudah dan praktis dalam kasus tertentu. 


\section{E. Pengaruh Penambahan Dispersion Compensating Fiber (DCF) dan Daya Transmitter terhadap SNR}

Selain dampak langsung pada BER, efek dari penambahan komponen dispersion compensating fiber (DCF) dan penambahan daya transmitter juga diamati pada SNR. Dengan penambahan $10.3 \mathrm{~km}$ DCF dengan konstanta dispersi -147 (ps/nm.km), nilai SNR masih memenuhi standar komunikasi untuk backbone $10 \mathrm{Gbps}$ per channel, yaitu $25 \mathrm{~dB}$. Namun, terjadi penurunan nilai SNR pada hampir semua channel. Puncak SNR terdapat pada frekuensi $193.5 \mathrm{THz}$ dengan SNR 67.7853. Hal ini disebabkan DCF memberikan atenuasi tambahan sebesar $0.24 \mathrm{~dB} / \mathrm{km}$ sehingga daya sinyal yang diterima menurun. Namun selebihnya, dispersi sinyal yang terjadi pada sebuah sistem transmisi optik tidak mempengaruhi nilai SNR secara langsung karena mempengaruhi transmisi dari segi bit data, bukan daya sinyal.

Lain halnya dengan penambahan DCF, optimasi berupa penambahan power menunjukkan hasil berupa SNR yang lebih tinggi atau sama dengan kondisi awal, namun hanya pada channel yang ditambah daya transmitternya. Justru pada channel lain, terjadi penurunan SNR. Penurunan yang paling besar terjadi pada channel 4 yaitu dari 53.95 menjadi 44.78 . Secara umum SNR tidak banyak dipengaruhi oleh kedua bentuk optimasi, baik penambahan DCF atau daya transmitter sehingga upaya tersebut dapat menjadi solusi untuk memaksimalkan kinerja sistem sesuai kebutuhan nilai BER.

\section{KESIMPULAN}

Hal yang dapat disimpulkan dari pelaksanaan studi ini diantaranya :

1. Telah dapat dilakukan analisis terhadap parameter Signal to Noise Ratio (SNR) dan Bit Error Rate (BER) dalam backbone komunikasi fiber optik segmen STO Lamongan 1 - STO Kebalen milik PT Telkom Indonesia melalui simulasi software Optisystem

2. Berdasarkan hasil simulasi, nilai SNR maksimum adalah 72.37 yang terdapat pada frekuensi 193.6 THz. Semua channel DWDM telah memenuhi standar nilai BER untuk komunikasi yaitu $10^{-6}$. Nilai BER minimum diperoleh pada frekuensi $193.5 \mathrm{THz}$ yaitu $2.05 \times 10^{-30}$

3. Untuk meningkatkan performa sistem menuju BER maksimum $10^{-12}$ dilakukan dua macam optimasi yaitu penambahan dispersion compensating fiber (DCF) dan penambahan daya transmitter. Sesuai hasil BER, penambahan sebesar $3 \mathrm{~dB}$ dilakukan pada channel 1 dan 10 , serta sebesar $1 \mathrm{~dB}$ pada channel 2 dan 9 .
- Penambahan DCF berhasil menurunkan BER maksimum ke $9.76 \times 10^{-16}$ dan memperlebar rentang kerja sistem dari 10 menjadi 16 channel

- Penambahan daya transmitter berhasil meningkatkan performa sistem dengan menurunkan nilai BER maksimum pada frekuensi tinggi dan rendah ke orde $10^{-10}$ dari nilai awal $10^{-6}$

- SNR tidak banyak dipengaruhi oleh kedua bentuk optimasi dan masih memenuhi nilai yang direkomendasikan yaitu minimal $25 \mathrm{~dB}$, walaupun terjadi penurunan di channel tertentu

\section{UCAPAN TERIMA KASIH}

Penulis mengucapkan terima kasih kepada PT Telkom Indonesia Divisi Regional 5 Jawa-Bali-Nusra, khususnya kantor Surabaya Ketintang dan STO Kebalen yang telah memberikan bantuan dalam proses pengumpulan data.

\section{DAFTAR PUSTAKA}

[1] D. U. I. and H. O. F. Idachaba, "Future Trends in Fiber Optics Communication," in World Congress on Engineering, 2014.

[2] S. V. Kartalopoulos, "Per-port Statistical Estimation of Bit Error Rate and Optical Signal to Noise Ratio in DWDM Telecommunications," Noise Commun. Proc. SPIE, vol. 5473, 2004.

[3] A. M. and A. Kusumawardhani, "Pengukuran Pengaruh Kelengkungan Serat Optik terhadap Rugi Daya Menggunakan Optical Time Domain Reflectometer (OTDR)," J. POMITS ITS, pp. $1-5,2009$.

[4] X. Y. and Y. Hechao, "The Application of OptiSystem in Optical Fiber Communication Experiments," in Third International Symposium on Computer Science and Computational Technology, Jiaоzио, 2010.

[5] B. F. D. and X. F. A. A. Khadir, "Achieving Optical Fiber Communication Experiments by OptiSystem," Int. J. Comput. Sci. Mob. Comput., vol. 3, no. 6, pp. 42-53, 2014.

[6] D. W. and C. X. G. Yan, Z. Ruixia, "Point-to-Point DWDM System Design and Simulation," in International Symposium on Information Processing, Huangshan, 2009.

[7] I. C. Union, ITU-T Handbook: Optical Fibre, Cables and Systems. Geneva: International Comunication Union, 2009.

[8] G. H. and Z. M. J. Alam, R. Alam, "Improvement of Bit Error Rate in Fiber Optic Communication," Int. J. Futur. Comput. Communiccation, vol. 4, no. 3, pp. 281-286, 2014.

[9] H. Z. and C. Zanger, Fiber Optics: Communication and Other Applications. Singapore: Maxwell Macmillan, 1991.

[10] G. Keiser, Optical Fiber Communications, 4th edition. Singapore: McGraw-Hill International Edition, 2010.

[11] G. P. Agrawal, Fiber-Optic Communication System, 3rd edition. New York: John Wiley \& Sons, 2002.

[12] I. T. Union, "ITU-T Recommendation G.671: Transmission Characteristics of Optical Components and Subsystems," 2012. 